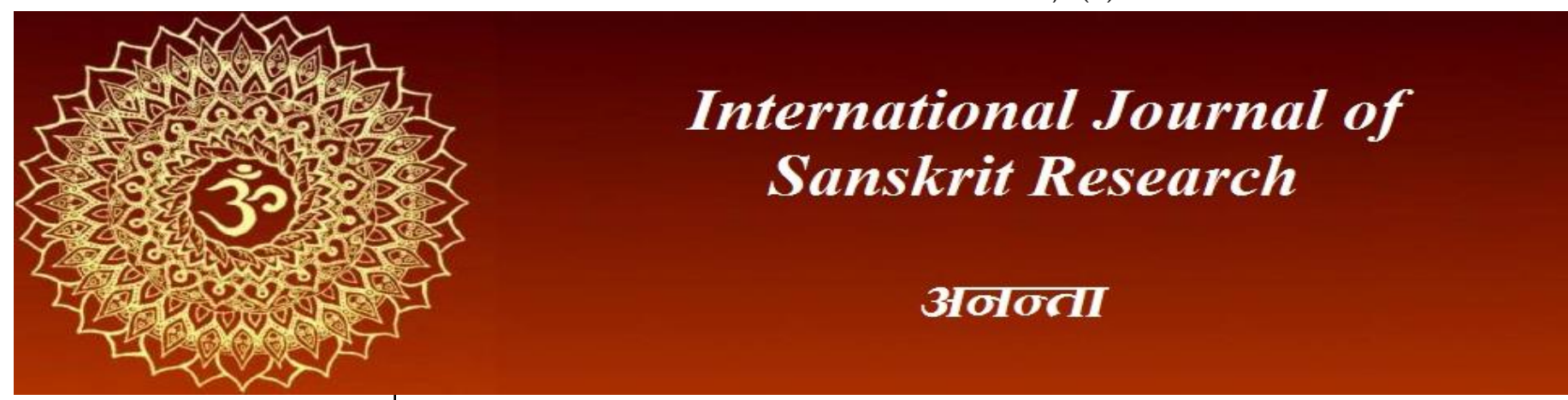

ISSN: 2394-7519

IJSR 2020; 6(5): 250-257

(C) 2020 IJSR

www.anantaajournal.com

Received: 08-07-2020

Accepted: 12-08-2020

Mahesh U Patil

Thane, Maharashtra,

India

\section{Legend descent of Ganga and similarities with impact event}

\section{Mahesh U Patil}

DOI: https://doi.org/10.22271/23947519.2020.v6.i5e.1148

\section{Abstract}

Role of comets and icy asteroids in getting water to Earth is under discussion for last few decades. In the recent history, we have observed and recorded two comet impact events in the solar system. Both the impacts of solwind and Shoemaker levy-9 support the argument that the impacts by comets may be a regular feature and Earth is no exception to it. In the history of mankind, there is a strong possibility that such events were observed by various civilizations.Early settlements of ancient India observed various celestial objects like stars, constellations, planets and comets.Vedas like Rigveda, Atharvaveda refer comets as "Dhumketu". Certain hymns of Rig Vedastrongly support the possibility of impact event being observed and recorded as eyewitness account. Reference of these celestial bodies is found in various ancient legends of India. These legends may be work of imagination based on real observations. One such legend is descent of Ganga from heaven. As per Valmiki Ramayana many aspects of this legend like its composition, appearance, descent path and effects at the time of descent have close resemblance with the impact event of a celestial body like comet. Ancient Stone carvings depicting the event provide major clue about the celestial movement and the impact event.In this paper we have used ancient description from Ramayana and Veda, and compared it with modern scientific facts and geological features of the region described in the legend.There are Multiple water bodies and lakes in the Tibet behind mount Kailash. This lake region is rich with finds like coesite, stishovite and other ultra high pressure finds that are usually associated with the impact site. These lakes play crucial role in the water cycle of Asia.Though there are lot of similarities in the legend and the available facts, as on date there is no conclusive evidence which can prove the origin of river Gangaas a result of this event as mentioned in thelegend. Thus this legend may be a result of observations mixed with belief.

Keywords: Comets, Ganga, Orion, Eridanus, mahabalipuram

\section{Introduction}

Impact event of solwind in 1979 and1994 shoemaker levy 9has drawn attention of the scientific community on the possibility of similar event on Earth. Even the Tunguska event is under discussion for possible comet impact. There are few sites like Egypt (Libyan Desert Glass region) which are under discussion for similar impact events but till date there is no conclusive evidence in the form of Cometary impact crater. Hence there is a strong possibility that modern science is missing something while studying impacts by these low density objects.One cannot ignore the possibility that such events were observed and may be recorded by early human settlements.Certain hymns of Rig Veda indicate the possibility of such event being observed by early Indian settlements. Thus there is no harm in considering their view point, however the main challenge is the method followed by the ancient civilizations for the recording and communicating these observations.In the ancient India one such event is recorded in the form of story which talks about water coming to earth from outer space in the form of river Ganga. For the purpose of this study we have referred the legend from Balkand of Valmiki Ramayana ${ }^{[1]}$ and its English translation by Ralph \& Grifith ${ }^{[2]}$.

Rivers are the main source of drinking water so they are respected in every culture. Rivers like Nile, Yangtze, Danube and other major rivers had a deep influence on the human civilization but no river is considered as holy as Ganga. This respect for Ganga is not restricted to any religion or region. 
For ages scholars, philosophers and rulers across the world were attracted tothe banks of Ganga and this attraction continues till date. One of the reason for this attraction lies in the story of its celestial origin with particular day of descent known as "Ganga dashmi" or "Ganga Dussehra". This story has such a deep impact on the Indian belief system that though this river flows from Himalayan mountains to the planes of northern India and ends at Bay of Bengal. people across India worship this river as goddess. Many sculptures and large stone carvings depicting even minute details of the story of its descent are well preserved in the temples of southern India. Apart from religious belief this story has a deep impact on the art, literature and dance. In Bharat Natyam (Dance Form) story ofits descent is depicted as Tanadav (Vigorousdance of Creation by lord Shiva). This influence of Ganga became more mysterious in the context of early Indian settlements, which were around the banks of Indus (Sindhu) and saraswati. Even in the oldest text of Rig veda, Saraswati and Sindhu (Indus) got more importance. For some strange reasons Ganga became important river in the ancient literature (Purana). later vedic writings, Ramayan and Mahabharat. This sudden shift in the belief system and story of its celestial origin with various astronomical references raise many questions. If we keep the belief aside and focus on the frame work of the story then it provides many clues which can be verified on the scientific parameters. In this study we have compared ancient references from the Ramayana with the modern perspective and scientific facts.. We have also considered other evidences which hint towards a possible eyewitness account of swarm impact being recorded in the form of rock art and ancient vedic writings.

\section{Method}

- Legend of Ganga: The Ancient References Vs Scientific Facts or Modern Perspective
- Vedic References \& Kashmir Rock Art

\section{Discussion}

Basic frame work of legend: As perValmiki Ramayana king Bhagirath performed a penance to bringGanga the daughter of Himavan, from heaven to the Earth. When the lord ordered Ganga to descend on Earth, there was a threat that Earth will not be able to handle its Vega (velocity or force). Thus lord Shiva agreed to hold Ganga in his hair (Jata). With great force Ganga fell on the head of Shiva but got trapped in the hair. For several years it kept revolving in the hair of Shiva and despite of all her efforts she could not come out of it.Bhagiratha once again requested lord Shiva to release Ganga on earth. Granting his request lord Shiva released Ganga from his hair in 7 parts or streams. Three main streams fell on the eastern side, 3 on the western side and $7^{\text {th }}$ stream followed the chariot of Bhagirathin the sky in all the directions where ever Bhagirath went. At the time of its descend on earth (Ganga Avataran) gods gathered to witness this event and their presence irradiated heaven (sky) as if thousand suns had risen. Ganga created lot of turbulence on the Earth.

Note: Many a times Purana (Ancient Literature) legends were a simplified stories based on Veda.since Vedas are complex to understand for common man. The ideology is similar to modern day science fictions where the core concept is communicated in the form of story which is easy to understand by masses.

\subsection{Description of Ganga and similarities with celestial object \\ Ancient References}

\begin{tabular}{|c|c|}
\hline इयं हैमवती गड्गा ज्येष्ठा हिमवतस्सुता। तां & Ganga, whose waves in heaven flow, Is daughter of the lord of snow. Win \\
वै धारयितुं शक्तो हरस्तत्र नियुज्यताम्। & Shiva that his aid be lent. To hold her in mid descent, For earth alone will \\
गड्गुगया: पतनं राजन् पृथिवी न सहिष्यति। & never bear those torrents hurled from upper air, and non may hold her \\
तां वै धारयितुं वीर नान्यं पश्यामि शूलिन: । & weight but he, the trident wielding deity (shiva)
\end{tabular}

Reference: Valmiki Ramayna Balkand (1) English Translation Raplph \& Grifith (2)

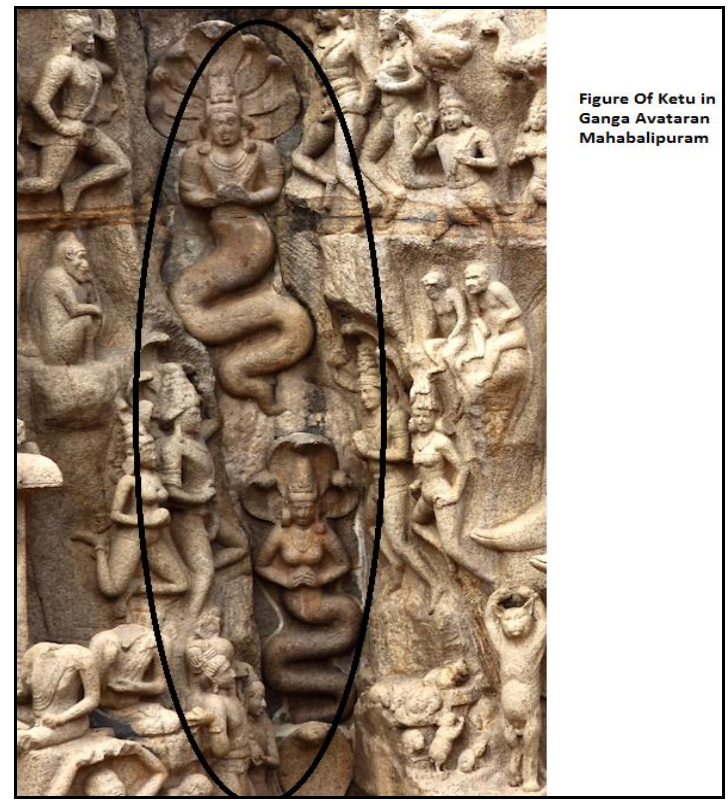

Fig 1: Stone carving at Mahabalipuram depictingdescent of Ganga. Photograph by Mahesh Balasubramanian 
Ganga, daughter of Himavan was movingin the heaven (word "hima" is used for snowe.g. Himalaya means abode of snow). Ancient Indians had knowledge about icy objects like comets which revolve around the Sun, In Sanskrit Comets are known as Dhumketu (Dhum means Smoke and Ketu is depicted as tail of a demon snake) This name explainsthe appearance of comet in the terrestrial planet zone where itstarts forming tail due to radiation effects. There are three ancient references which hint towards close resemblance of Ganga with comet.

A. The famous Ganga avatarn sculpture at Mahabalipurm depicts Ganga in the form of 3 ketus (as 3 streams descending on earth) Figure 1. As described earlier in Sanskrit Comet is known as "Dhumketu" (Dhum is smoke and Ketu is depicted as tail of demon snake).

B. Sculpture at Kailasnath Temple Kanchipuram, depict Ganga as celestial body with tail, its shown near constellation Orion and Canis minor (Figure 2)

C. As per "ShreemadBhagvat" 10.70.44Transcendental water of Gangatravelledthroughout entire universein higher, lowerplanetary system and Earth. In higher planetary system she is called "Mandakini" ("She who Flows Calmly/ Elegantly")in lower planetary system known as "Bhogavati" ("serpentriver" may be because of tail formation) and on Earth she is known as Ganga.These three stages hint towards a celestial body like Comet which came from beyond Jupiter region and change its shape (serpent shape) before impacting the Earth.

\section{Scientific facts and modern practices}

In our solar system icy bodies are beyond asteroid belt. They are in the form of asteroids. comets and moons. Comets are concentrated on the extreme edge of the solar system near the oort cloud and Kuiper belt and keep orbiting around the Sun. According to modern science Earth has got most of its water by impact of icy objects like asteroids and Comets. Deuterium level in the ocean water is similar to water found in Comets thus modern science believe that Comets may have played a major role in getting water and life to our planet.When it comes to referring these objects, even today we refer these various celestial objects with their names rather than its compositioneg.Comets like Hale Bopp, Halley are known by the names of people who discovered them.

\subsection{Why descent of Ganga was dangerous}

\section{Reference: Valmiki Ramayna Balkand (1) English} Translation Raplph \& Grifith (2)

\section{Ancient Reference}

When lord asked Ganga to descent on Earth, she was unwilling to go and threatened that the Earth will not be able to take Vega (velocity) of her descent. It may cause destruction on Earth.

\section{Scientific Facts: Threat Of high velocity Impact}

It's a known fact that the hyper velocity impact of large asteroids and Comets are capable and responsible for destruction and mass extinctions from Earth. Shoemaker levy -9 (3) event has drawn attention of the world to this threat. Even Tunguska event is under discussion for possibility of a impact by a small comet.

\subsection{Celestial reference and its position in the night sky}

He held the river on his head, and kept her wandering, where, dense as Himalaya's woods, were spread the tangles of his hair.

Reference: Valmiki Ramayna Balkand (1) English Translation Raplph \& Grifith (2)

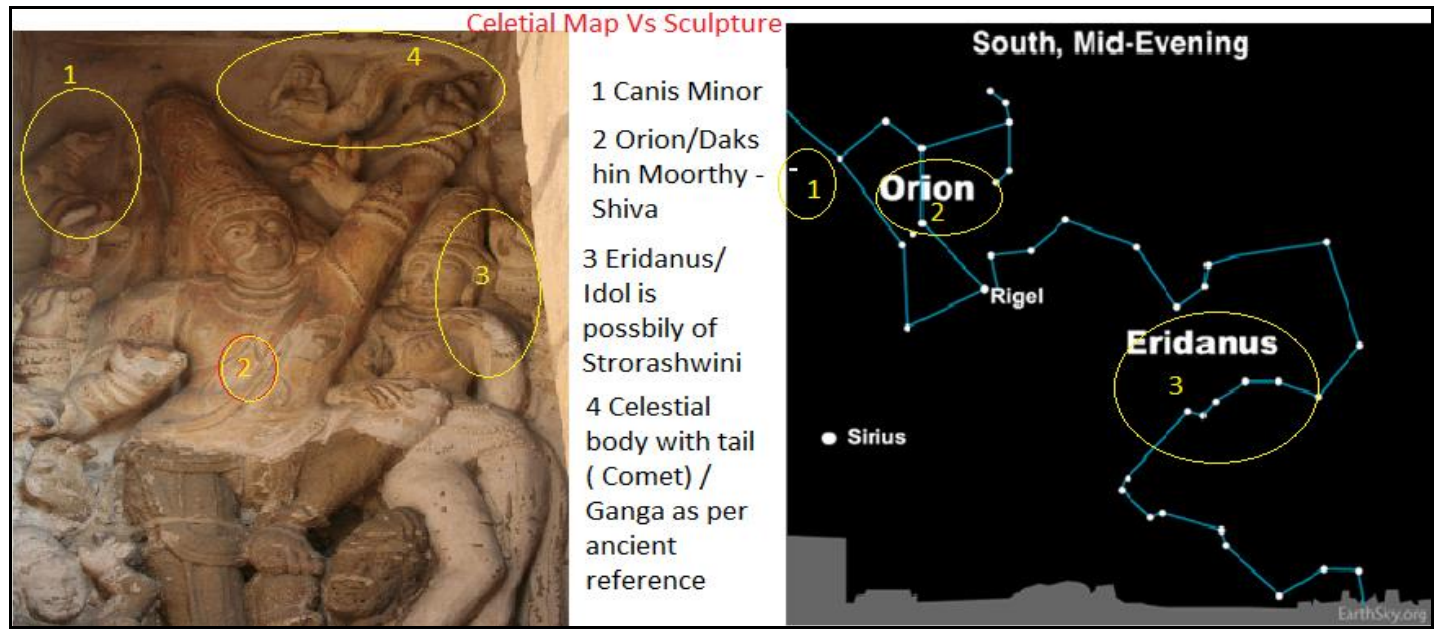

Fig 2: Shivaganga Dhara, Kailash Nath Temple, Kanchipuram Source: http://www.chidambaramhiddentreasure.com/gangadhara/ 
Canis Minor (depicted as dog in most of the ancient cultures)

2) Orion 3) Lady which may be representing Eridanus/ Strotashwini4) Ganga represented as Celestial Body with tail

\section{Ancient Reference}

Considering the threat, lord Shiva agreed to hold Gang on his head. With great force Ganga fell on the head of Shiva and followed the path of Strotashwini (Eridanus) while heading towards the Earth. In the celestial context Shiva is also known as Natraj or Dakshinmurthy and represented by constellation Orion.Eridanus is called strotaswini (meaning course of river Ganga). This event is very well covered in a sculpture at "kailasanatha temple, Kanchipuram"and few other temples of southern India depicting Shiva as Gangadhar (One who is holding Ganga) Figure2. As per one of the version of the story, this event occurred on Saptami ( $7^{\text {Th }}$ day) of Vaishakh month's shuklapaksha (waxing Moon) thus known as Ganga Saptami. Sculpture hint towards 4 key references of the night sky.Orion, Canis Minor, Celestial object with tail (Ganga) and a female figure may be of Eridanus (Strotashwini)

\section{Modern Perspective}

Even today we refer constellations to spot the locations in the night sky.

\subsection{Disintegration of Ganga in Space} until her pride were tamed, amid his locks to rove. There, many lengthening seasons through, a wildered river ran. And sinking into Vindu's lake here weary waves descend. From Ganga, by the God set free, seven noble rivers came.

Reference: ValmikiRamaynaBalkand (1) English Translation Raplph \& Grifith (2)

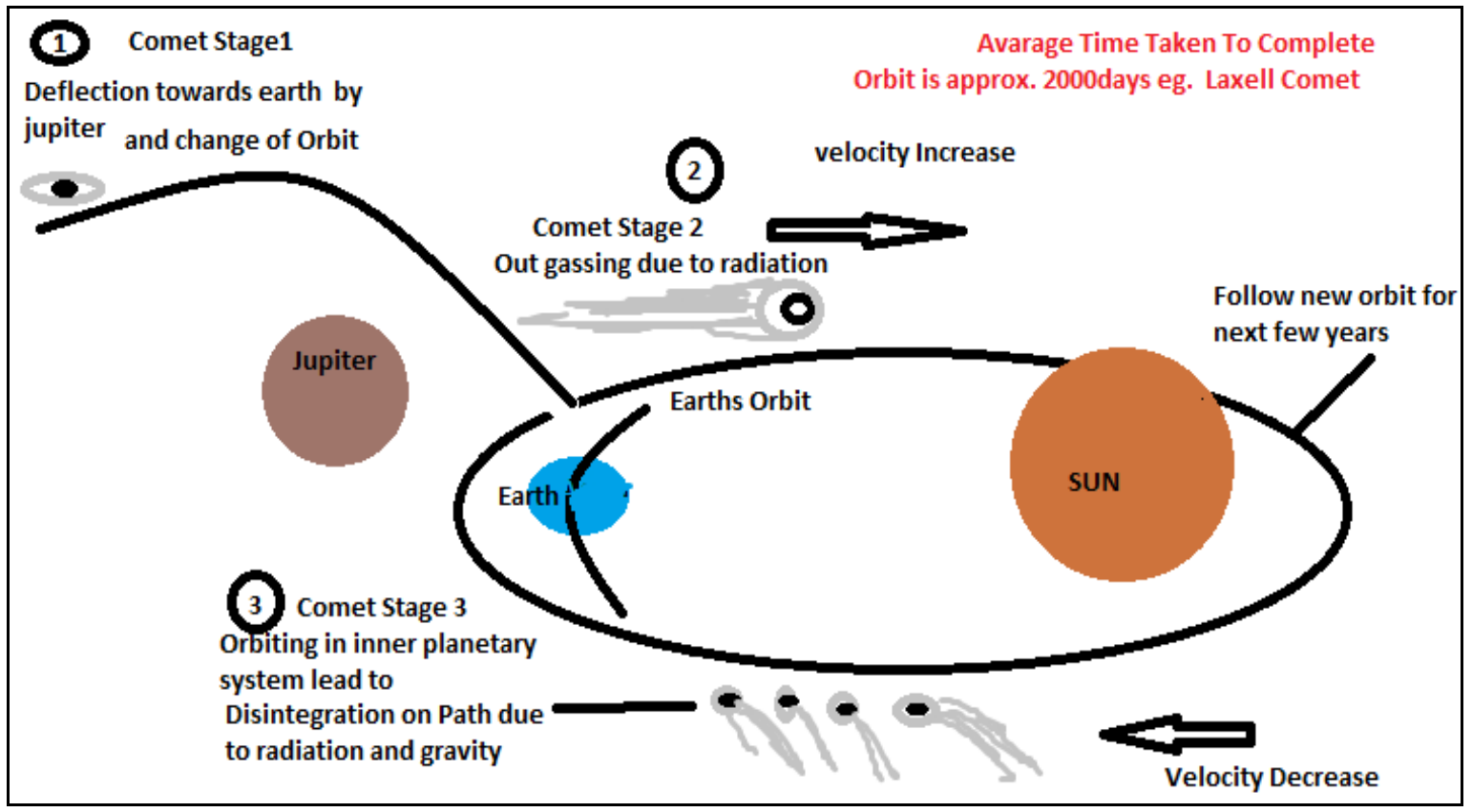

Fig 4: Artistic presentation of disintegration of comet

\section{Ancient Story}

After appearing on the Shiva'shead (Dakshinmoorthy/Orion), Ganga was trapped in his hair (jata) and despite of many efforts she could not come out of the shiva's hair. Ganga kept revolving for many years and disappeared from the sight. Concerned with thisBhagirath (Who brought Ganga on Earth) requested lord Shiva to release Ganga. Granting the wish, Shiva released Ganga which got disintegrated in 7 parts. These seven parts formed 7 streams which fell on the Earth.

\section{Scientific Facts}

Comets from oort cloud and Kuiper belt that are deflected towards the inner interplanetary region by Jupiters gravity undergo change of Orbit and are trapped in the terrestrial planet zone. Such comets are known as short period comets. These comets can have orbital period as short as 5-6 years, due to this short orbit they keep appearing and disappearing at regular intervals. These short period comets tend to disintegrate under the influence of Sun's heat and tidal forces in the terrestrial planet zone (Figure 4). There are multiple evidences of disintegration, In the recent history we have observed and recorded the impact of disintegrated Comet "Shoemaker Levy-9" (3) with Jupiter. Thus both the points that Ganga kept on revolving for many years and disintegrated in 7 parts have similarities with properties of short period comet.

\subsection{Impact Event of Ganga and Impact Location}

ह्लादिनी पावनी चैव नलिनी च तथाऽपरा। तिस्र: प्राचीं दिशंजग्मु:गड्गंशिवजलाश्शुभा:। सुचक्षुश्चैव सीता च सिन्धुश्चेव महानदी। तिस्रस्त्वेता दिशं जग्मु: प्रतीचीं तु शुभोदका:। सप्तमी चान्वगात्तासां भगीरथमथो नृपम्। भगीरथोऽपि राजर्षिर्दिव्यं स्यन्दनमास्थित:।
Haldini, Pavani and she called Nalini by name: These rolled their lucid waves along and sought the eastern side. Suchakshu, Sita fair and strong, and sindhu might tide these to the region of west with joyfull waters sped. Seventh biggest and the best, flowed where Bhagirath led. On Shiva's head descending first a rest the torrents found; Then down in all their might they burst and roared along the ground. 
Reference: Valmiki Ramayna Balkand (1) English Translation Raplph \& Grifith (2)

\section{Ancient Reference}

As per Purana (ancient literature). On the 10th day (dashmi) of the waxing moon (Shukla Paksha) of the Hindu calendar month Jyeshtha (Period between May and June). 3 main streams of Ganga landed on the eastern sideand three landed on the western side (with reference to mount Kailash) $7^{\text {th }}$ stream followed the chariot of Bhagirath In the sky and went in all directions. This event is very well depicted in the ancient sculpture at Mahabalipuram "descent of Ganga" (figure5) which showcase 3 main streams falling on the Earth with gods, animals and humansare observing this event with curiosity.

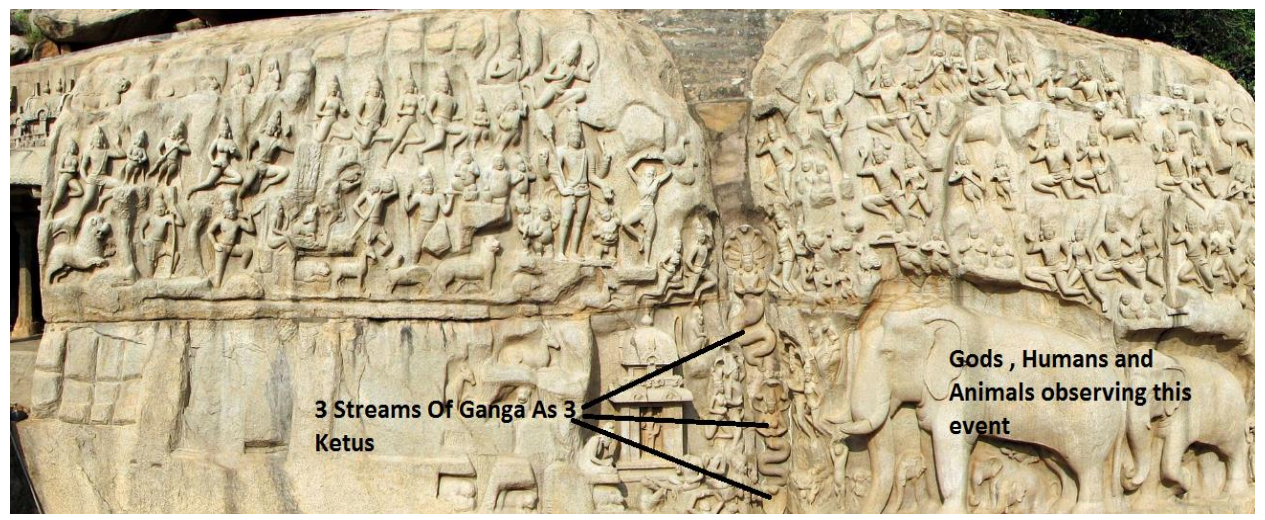

Fig 5: Stone Carvingat Mahabalipuram

\section{Modern perspective and scientific facts}

In case of shoemaker levy -9 impact (3), we have observed each fragment impacting at different time interval creating east to west pattern. It's quite possible that these 7 fragments entered in the Earth's atmosphere over a period of short duration and due to Earth's rotation this appeared as East to West impact pattern. These fragments once entered in the Earth's atmosphere would have undergone plume formations, which may have been assumed or interpreted as streams falling from the sky. In the event of impact by icy objects some fragments may impact the Earth but small fragments may airburst similar to Tunguska event. Thus legend may be hinting towards 6 impacts and one ( $7^{\text {th }}$ fragment) airburst which went in all directions.

If We look at the area behind Mount Kalilash, we can observe multiple lakes (figure6). These lakes have Deuterium enrichment with sharp fluctuation around 6000 years back.

\section{Dilemma of modern science: comet impact or comet airburst (vaporize)}

Roddy (4) \& O'Keefe (5) and others have tried to understand the impact of low density $\left(<1 \mathrm{~g} / \mathrm{cm}^{3}\right)$ objects like Comets. They have tried to differentiate the impact craters of comet from asteroids. This work can help us to understand many other possible impact sites but till date most of the investigations are carried out basis impact features of rock and metal asteroids having density of $\geq 1 \mathrm{~g} / \mathrm{cm}^{3}$. One of the reason for this may be a general belief / assumption that a fragile objects like comet will airburst due to friction with Earth's atmosphere. This may hold true for smaller fragments but may not apply in every case. We cannot ignore two key observations in the recent human history 1) 30 Aug 1979, when comet C 1979 Q1 (Solwind) impacted the surface of the Sun 2) July 1994 When Comet Shoemaker Levy 9entered Jupiter's atmosphere and formed large plumes.Both the events substantiate the fact that the Comet can survive extreme temperatures and atmospheric conditions and may not burst or vaporize instantly. These two observations at such a short interval also force us to think about the frequency of such events.

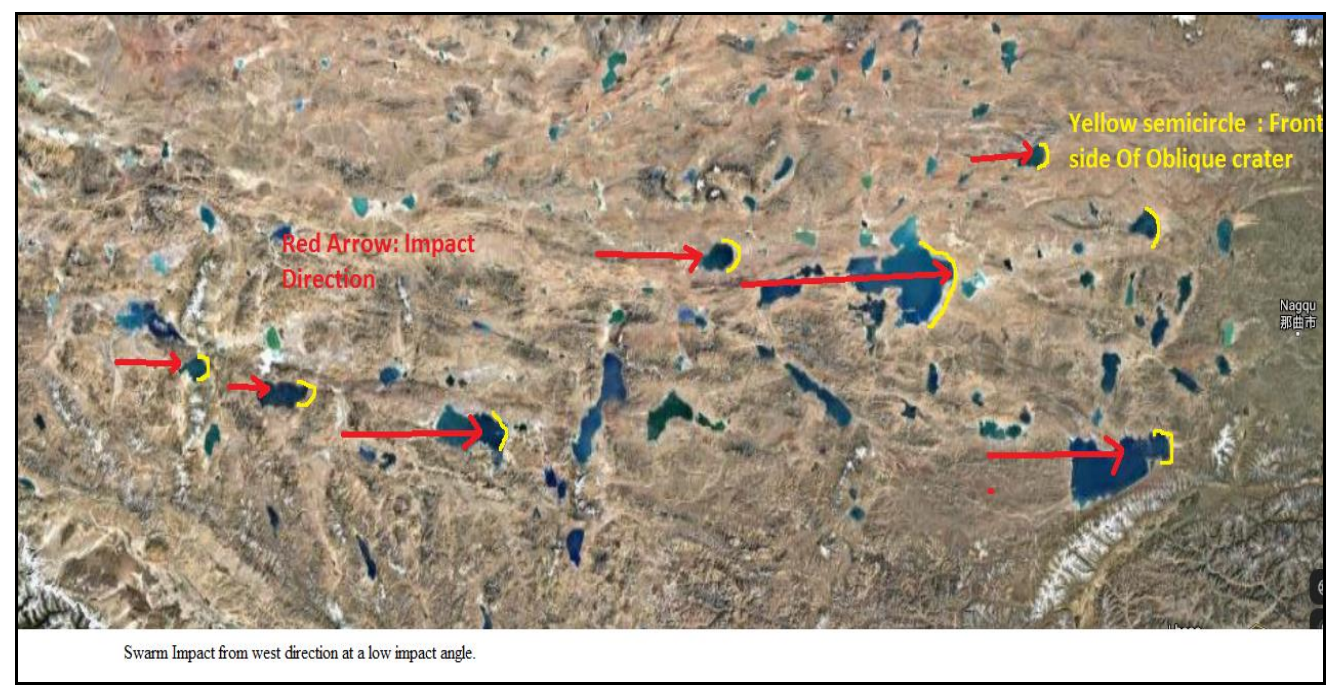

Fig 6: Lake Region in Tibet and Proposed impact pattern 


\subsection{After effects of impact and other developments}

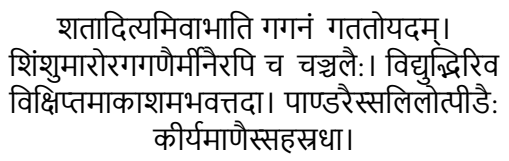

The cloud less sky was all aflame with the light of hundred suns where're the shinning chariots came. That bore those holy ones. So flashed the air with crested snakes and fish of every hue, as when lightning glory breaks through fields of summer blue. And white foam- clouds and silver spray were wildly tossed on high, like swans that urge their homeward way across the autumn sky.
Reference: Valmiki Ramayna Balkand (1) English Translation Raplph \& Grifith (2)

\begin{abstract}
Ancient Reference
Despite of Shiva holding Ganga in his hair for several years and disintegrating it at the time of release, streams of Ganga fell on the Earth with lot of energy and making lot of noise, as per Ramayana sky (heaven) was irradiated as if hundred suns had risen there, white clouds like crested snakes with glow were observed.At the time of impact rushing water of Gangacreated lot of turbulence. This act disturbed Sage Jahnu and he Swallowed water of Ganga to punish this act. On request of Bhagirath to release this holy water to fulfill their need, sage released Ganga.
\end{abstract}

\section{Modern Perspective}

Eyewitness accounts of Tunguska, Cheliyabinsk meteor have described the bright light. noise level and shock wave of such events as described in the legend. Such impact events create ultra high pressure and temperature and cause lot of disturbance that may have long lasting effects on the geology.
This brings many physical and chemical changes on the ground. If we look at the lake region of southern Tibet, we will find lot of faults and fractures interconnecting these lakes, such faults are developed in the ultra high pressure event. It's possible that impact lade to formation of these lakes and water started trickling down thru these faults and started a new network of water channels above and below the surface. These lakes are source of Yarlungzangbo River (Bramhaputra).

There are many unique minerals reported from Yarlungzangbo region of Tibet which can be associated with the impact event, as described by Patil et al. ${ }^{[6]}$. Minerals like cubic Boron Nitride, Boron carbide in natural environment are exclusive to Tibet and can be explained only by either impact event or deep mantle origin, impact of a comet provide a better explanation for their existence. Finds like osbornite (TiN), Coesite after stishovite and microdiamond in the region along with the tektite strewn fields in Asia, strongly support the possibility of impact.

\subsection{Possible Casualties}

Then they whom heavenly doom had hurled, Accursed to this lower world, Touch the pure wave, and freed from sin resought the skies and entered in.

\section{Reference: Valmiki Ramayna Balkand (1) English Translation Raplph \& Grifith (2)}

\section{Ancient Reference}

Based on Valmiki Ramayana it seems that the impact event caused some casualties.

\section{Modern Perspective}

Such catastrophe can result in to loss of life. In the Tunguska event some casualties were reported but since the impact occurred in a remote region not so densely populated the numbers were limited.

\subsection{Disconnect}

\section{Ancient Reference}

As per legend and belief Ganga originates from lake Manas which is near mount Kailash. From this location it travels underground and appears at Gangotri / Gomukh (Figure 7)

\section{Scientific Facts}

These lakes are behind mount Kailash in the region further away from Manas lake and they are spread over a much larger area. These lakes are source to Yarlungzangbo (Bramhaputra) (Figure 7) but as one date there is no evidence that these lakes are connected to river system of Ganga in any way. It also does not provide any clue whether this event was responsible to start the river system of Ganga.

\section{Assumption of vantage point}

If we assume that this event was observed from foothills of Himalaya (Figure7). Then observer will see plume formation in the sky above Himalayn region. Since the mount Kailasah has a great importance in the belief system of India for ages, it would have been referred as the point to spot the impact location. Thus, this event would have been recorded as three main Streams (Plumes) falling on the east direction and three others in the west direction of mount Kalilash.

Location of Impact, behind Mount kailash and spotting of comet over Orion (Dakshinmoorthy/Shiva) might have played a key role in the association of Shiva with impact event as described in the legend

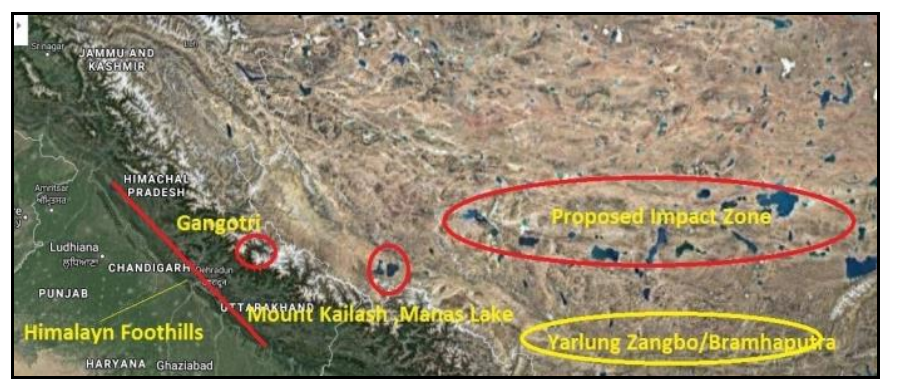

Fig 7: Location of Gangotri, Mount Kalilash, Proposed Impact Zone and Yarlungzangbo/ Bramhaputra 


\section{Other ancient evidences of comet impact}

Apart from legend of Ganga there are other observations, which strongly indicate the possibility of swarm impact of comet being observed by ancient Indian settlements. Some of these observations are part of Vedas like Rigveda and Atharvaveda. These ancient references on Comets are discussed by R.N.Iyengar et al. ${ }^{[7]}$. These references strongly hint towards the observation of swarm impact of Comet. Apart from this a rock art in Sopore district of Kashmir is already under discussion for possible record of comet impact observation.

\section{A. Vedic Reference}

Vedas are collection of hymns and other religious text which covers various aspects including cosmology. Rig-Veda and Atharvaveda refer comet as Dhumketu. A study by R.N. Iyengar ${ }^{[7]}$ has discussed the comets and meteoritic showers mentioned in Rigveda. These references strongly support that the ancient Indians had observed an impact event of a celestial body like comet.

Important points from the paper "comets and meteoritic showers in Rigveda"

A. It is recorded as "Adbhut" (strange/ not normal) event

B. Comet was observed previously at many dawns

C. It is in the form of transient fire

D. Its roaring and driven by red animals

E. It is in the form of multiple fiery objects with smoky extensions

F. Observer is requesting for protection from this fire

G. Drops of this fire eat/burn grass

Apart from these observations an important phenomenon of "Bhasaketu" has similarities with phenomenon of noctilucent clouds observed in the night sky post impact.
Yamâsâ kr. pani.lambhâsâketumvardhayanti | bhrâjates fren. Idan

Bhasaketu is described with following properties:

-flame bannered fire or one who gives out light and in next verse it is described as 'who when he moves up penetrates the ends of the sky, illumining the firmament'.

- As one that is standing above the sacrificial altar.

- Fire is described to 'move straight in a big car showing colours, white, black, red and crimson'.

-This fire 'measures the fireplace by his movements' or bright celestial object that was stationary for some time and then started moving as though measuring the sky

These observations are in line with luminescent clouds observed post Tunguska event.In the event of impact by comet noctilucent clouds can be formed at the height of 80 $100 \mathrm{~km}$ (highest clouds in the sky) above the impact site. Such clouds can be observed and recorded over a long distance. It is quite possible that these clouds were observed from various parts of northern India especially from the Himalayan region.

\section{B. Kashmir- SoporeRock Art}

A rock art (figure 8) from Bomai village in Soporeregion of Kashmir is under study for possible record of comet impact. The study byM.N.vahia and Naseer Iqbal et al. ${ }^{[8]}$ Suggest that the bright objects are shown in the art using multiple concentric circles. Size of the circle is indicative of brightness. Rock art indicate objects originate in the north west direction and falls towards south east direction (this direction is in line with proposed impact site). It is believed that this art is between $40000 \mathrm{BP}$ to $6000 \mathrm{BP}$.

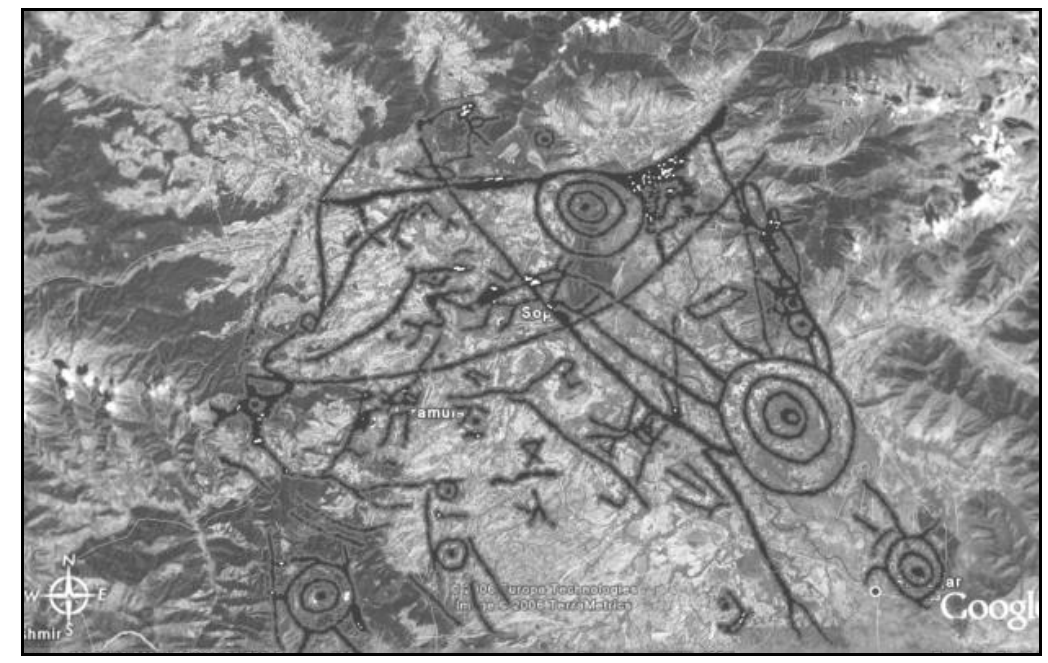

Fig 8: Rock Art from Bohmai Village, Kashmir. Possible record of Comet Impact Observation.

These details can only be recorded by early settlements if person has experienced such event. This strongly hints towards the possibility that ancient Indians observed an impact by disintegrated comet.

\section{Possible co relation between sopore rock art and Vedic observations.}

As mentioned earlier, Veda has used a term Bhasaketu which has lot of similarity with noctilucent clouds. There is a strong possibility that such clouds were observed by ancient settlements in Kashmir. Proposed comet Impact zone is close to $750-1500 \mathrm{~km}$ away from observer in sopore (Figure 9). Thus it is not in the visible range. However since noctilucent clouds are the highest clouds formed close to $100 \mathrm{~km}$ above the ground. (Veda refer Bhassaketu as "moves up penetrates the ends of the sky, illumining the firmament".) Thus observer in Sopore might have seen plume formation at the time of impact followed by bright luminescence in the night sky which they recorded as concentric circle. 


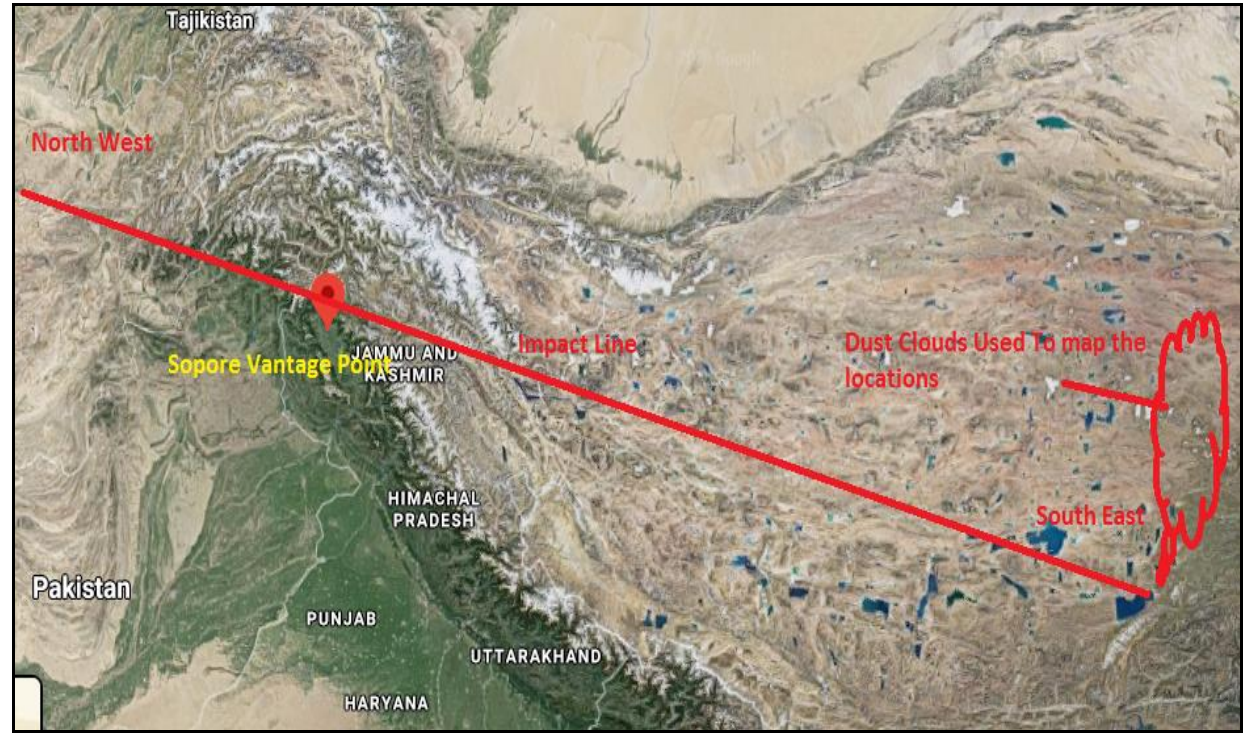

Fig 9: Vantage point: Sopore and proposed impact location

\section{Conclusion}

The legend of Ganga has many similarities with the impact event of a comet that might have occurred in the southern Tibet behind mount Kailash.Various stone carvings and descriptions in the local legend indicate the similarity with impact of celestial body.Modern findings of rare minerals, and other findings support the impact possibilities. The lakes in the proposed impact region play important role in the water cycle of Yarlungzangbo (Bramhaputra), however as on date no evidence is available that can co relatethese lakes in the possible impact sites with the source of river Ganga. It also does not provide any evidence that the flow of existing river Ganga was initiated as a result of this impact. Thus its possible that the legend was a result of observations mixed with belief. Ancient rock art in Kashmir and possible comet impact descriptions in the Veda strongly support the possibility of such event being observed by early settlements in India. This also supports the modern belief that comets might have played a crucial role in getting water to the planet Earth.

\section{Reference}

1. Shreemad Valmiki Ramayan, Translated into Hindi by Chaturvedi Dwarkaprasad Sharma. Published by Ramnarayan Lal Publisher \& book seller, Printed by Ramzan Ali Shah at National Press Allahabad, 1927.

2. The RÁMÁYAN of VÁLMÍKI" Translated into English Verse by Ralph T. H. Griffith.Published in London by Trübner\& Co., and published in Benares by E. J. Lazarus and Co, 1870-1874.

3. HammelHB. HST Imaging of Atmospheric Phenomena Created by the Impact of CometShoemaker-Levy. 9Science $1995 ; 267: 1288-1296$.

https://doi.org/10.1126/science.7871425

4. RoddyDJ. High Explosive Crateringanalogs for bowled shape, Central Uplift, central uplift, and multiring impact craters, Lunar Science Conf. $7^{\text {th }}$. 1976, 3027-3056.

5. O'Keefe, Cometary and Meteorite Swarm Impact on Planetary Surface. Journal of Geophysical Research, Vol 87.No.B8Page 6668-6680 August 10.1982 S.B. 10.70.44

6. Patil et al. High-Pressure Nitrides And Micro Diamonds From Tibetan Ophiolite, OJG, 2019; 9:13.
7. Iyengar RN.Comets and Meteoritic Showers in the R.Gvedaand Their Significance, Indian Journal of History of Science. 2010; 45(1):32.

8. Vahia MN et al. The Prehistoric Meteor Shower Recorded on A Paleolithic Rock. Nriag Journal of Astronomy and Astrophysics, 2008, 469-475. 